\title{
Akurasi Pulse Oksimetri Fingertip Dibandingkan Pulse Oksimetri Generasi Baru dalam Deteksi Dini Penyakit Jantung Bawaan Kritis pada Bayi baru Lahir: Penelitian Pendahuluan
}

Ina Rochayati, Sukman Tulus Putra, Bambang Supriyatno

Departemen Ilmu Kesehatan Anak Fakultas Kedokteran Universitas Indonesia /Rumah Sakit Cipto Mangunkusumo, Jakarta

Latar belakang. Peningkatan morbiditas dan mortalitas bayi baru lahir dengan penyakit jantung bawaan kritis berkaitan dengan diagnosis yang terlambat.

Tujuan. Mengetahui nilai diagnostik pulse oksimetri fingertip dibandingkan generasi baru untuk deteksi dini PJB kritis pada bayi baru lahir.

Metode. Penelitian dilakukan di Ruang Rawat Gabung RSCM pada bayi bugar, usia gestasi $\geq 37$ minggu, dan berusia 24-72 jam. Oksimetri dilakukan di tangan kanan (preduktal) dan kaki (postduktal). Subjek dengan $\mathrm{SpO}_{2}<95 \% / b e d a>3 \%$ antara tangan kanan dan kaki diperiksa lebih lanjut.

Hasil. Pada 442 bayi, SpO preduktal kedua jenis pulse oksimetri bervariasi secara statistik namun tidak bermakna klinis. Tidak ada subjek dengan hasil deteksi positif dan didiagnosis PJB kritis melalui pemeriksaan oksimetri.

Kesimpulan. Uji diagnostik pulse oksimetri fingertip dibandingkan generasi baru untuk deteksi dini PJB kritis pada bayi baru lahir pada penelitian ini belum dapat dinilai. Sari Pediatri 2015;17(2):113-8.

Kata kunci: PJB kritis, pulse oksimetri, uji diagnostik

\section{Comparison between Fingertip and New Generation Pulse Oximetry Accuracy in Early Detection of Critical Congenital Heart Disease in The Newborn: Preliminary Study}

Ina Rochayati, Sukman Tulus Putra, Bambang Supriyatno

Background. Late diagnosis in the newborn with critical congenital heart disease (CCHD) is associated with increased morbidity and mortality.

Objective. To estimate diagnostic study results of fingertip pulse oximetry screening compared to a new generation to detect CCHD in the newborn before hospital discharge.

Methods. This was a diagnostic study held in newborn nursery of Cipto Mangunkusumo Hospital involving asymptomatic newborns aged 24-72 hours and gestational age $\geq 37$ weeks. Examination of fingertip and new generation pulse oximetry was done in right hand (preductal) and foot (postductal). Subject had oxygen saturation $<95 \%$ or difference of oxygen saturation between right hand and foot $>3 \%$ requires further investigation.

Results. In 442 asymtomatic newborns, obtaining preductal oxygen saturation using two types pulse oximetry varied statistically but not clinically significant. No subject had positive detection result and was diagnosed CCHD through screening oximetry.

Conclusion. Diagnostic test of fingertip compared with new generation pulse oximetry in early detection of CCHD in this study can not be assessed. Sari Pediatri 2015;17(2):113-8.

Keywords: critical congenital heart disease, pulse oximetry, diagnostic study

Alamat korespondensi: Dr. Ina Rochayati, Sp.A. Departemen Ilmu Kesehatan Anak Rumah Sakit Cipto Mangunkusumo, Jl. Diponegoro No. 71, Senen, Jakarta Pusat. Telp +62 21391830111 . E-mail: inarochayati@yahoo.com 
$\mathrm{P}$ enyakit jantung bawaan (PJB) kritis merupakan kelompok kelainan jantung bergantung duktus atau PJB yang membutuhkan operasi atau intervensi dalam bulan pertama kehidupan. ${ }^{1}$ Peningkatan mortalitas akibat PJB kritis berkaitan dengan diagnosis yang terlambat. ${ }^{1-5}$ Diagnosis PJB kritis yang terlambat dapat menyebabkan bayi mengalami kardiak katastropik serta kegagalan multi-sistem setelah duktus menutup. ${ }^{2,3}$ Sekitar 30 (13-48)\% bayi baru lahir dengan PJB kritis tidak terdiagnosis hingga pulang dari rumah sakit. ${ }^{2} \mathrm{Di}$ Indonesia, rendahnya angka kelahiran di rumah sakit mungkin menyebabkan lebih banyak bayi baru lahir dengan PJB kritis tidak terdiagnosis dini. Data nasional menunjukkan $84,72 \%$ kelahiran bukan di rumah sakit. ${ }^{6}$

Pemeriksaan pulse oksimetri pada bayi baru lahir sebelum pulang dari rumah sakit dapat membantu mendeteksi dini PJB kritis. ${ }^{2,3,7-10}$ de-Wahl Granelli $\mathrm{dkk}^{7}$ melaporkan peningkatan angka deteksi hingga $92 \%$ defek bergantung duktus. Peran pulse oksimetri untuk deteksi dini PJB kritis didasarkan pada kemampuan mengenali penurunan saturasi oksigen $\left(\mathrm{SpO}_{2}\right)$ sebelum timbulnya manifestasi klinis nyata seperti sianosis. ${ }^{11,12}$

Pada praktiknya, pulse oksimetri untuk skrining PJB kritis belum digunakan secara universal. Terdapat anggapan bahwa diagnosis kelainan jantung cukup dilakukan melalui pemeriksaan fisis saja, pulse oksimetri tidak dapat diandalkan, dan keberatan dengan biaya. ${ }^{2}$ Faktor biaya tersebut antara lain biaya staf pelaksana dan alat untuk skrining dan diagnostik. Untuk faktor alat, terdapat pulse oksimeter fingertip dengan kelebihan ukuran kecil, mudah dibawa dan digunakan, serta harganya terjangkau. ${ }^{14,15}$ Penelitian ini bertujuan untuk mengetahui angka kejadian dan jenis PJB kritis hasil skrining pulse oksimetri, dan sebagai uji diagnostik pulse oksimetri fingertip dalam deteksi dini PJB kritis pada bayi baru lahir.

\section{Metode}

Uji diagnostik dilakukan secara potong lintang (Juli 2013-Januari 2014) menggunakan pulse oksimetri fingertip yaitu Onyx $\mathrm{II}^{\circledR}$ dibandingkan dengan baku emas pulse oksimetri generasi baru yaitu Masimo SET Radical $7^{\circledR}$. Penelitian dilakukan di Ruang Rawat Gabung Gedung A RSCM. Kriteria inklusi adalah bayi baru lahir bugar, usia gestasi $\geq 37$ minggu dan berusia 24-72 jam. Kriteria eksklusi adalah orang tua menolak berpartisipasi.

Jumlah sampel yang diperlukan minimum 860 subjek. Subjek penelitian dipilih secara konsekutif hingga besar sampel minimal terpenuhi atau penelitian telah berlangsung 6 bulan. Pada tahap pra-penelitian, 30 bayi dilakukan oksimetri sesuai kriteria dan alur penelitian untuk mengetahui peluang penggunaan Onyx II ${ }^{\circledast}$ pada bayi baru lahir, hambatan pemeriksaan, dan efek yang tidak diharapkan. Peneliti dan/atau asisten peneliti (asisten peneliti adalah perawat yang telah mendapatkan pelatihan tentang prosedur penelitian ini), sebanyak 2 orang, melakukan pemeriksaan saat subjek tenang. Kedua jenis oksimetri dilakukan secara bersamaan di tangan kanan, selanjutnya di kaki kanan memakai Masimo SET ${ }^{\circledR}$ dan kaki kiri dengan Onyx $\mathrm{II}^{\circledR}$. Sensor Masimo SET ${ }^{\circledR}$ direkatkan di telapak tangan kanan/kaki sehingga dioda dan fotodetektor saling berhadapan selanjutnya sensor dipasang pada kabel oksimeter. Onyx II ${ }^{\circledR}$ direkatkan pada jari hingga telapak tangan kanan/kaki bayi dan dipastikan tangan/ kaki berada di antara dioda dan fotodetektor. Setiap pemeriksa meneliti satu jenis oksimetri, mencatat waktu yang diperlukan saat $\mathrm{SpO}_{2}$ maksimal dan frekuensi nadi stabil. Pemeriksaan dilanjutkan hingga oksimetri telah berlangsung 1 sampai 2 menit.

Hasil pemeriksaan $\mathrm{SpO}_{2}$ dibagi menjadi 3 kriteria, yaitu (1) $\mathrm{SpO}_{2} \geq 95 \%$ di tangan kanan dan kaki, atau perbedaan $\leq 3 \%$ antara tangan kanan dan kaki, disebut hasil deteksi negatif maka pemeriksaan dihentikan; (2) $\mathrm{SpO}_{2}<90 \%$ di tangan kanan atau kaki, disebut hasil deteksi positif; (3) $\mathrm{SpO}_{2} 90-<95 \%$ di tangan kanan dan kaki, atau perbedaan $>3 \%$ antara tangan kanan dan kaki. Jika hasilnya memenuhi kriteria 3 maka oksimetri dilanjutkan 1 jam kemudian. Apabila hasil pemeriksaan memenuhi kriteria 3 kembali disebut hasil deteksi positif, dan apabila berbeda maka merujuk kriteria lain yang terpenuhi. Pemeriksaan ekokardiografi dilakukan pada hasil deteksi positif dengan Masimo SET ${ }^{\circledR}$.

Perolehan hasil deteksi digunakan untuk menghitung sensitivitas, spesifisitas, nilai duga positif dan negatif, rasio kemungkinan positif dan negatif, pretest- dan posttest-probability. Perbedaan perolehan $\mathrm{SpO}_{2}$ antara pulse oksimetri fingertip dan generasi baru dinilai dengan Uji Bland Altman, perbedaan waktu yang diperlukan untuk mencapai hasil maksimal dinilai dengan Wilcoxon signed rank test. Interval 
kepercayaan adalah 95\%. Nilai $\mathrm{p}<0,05$ dianggap statistik bermakna.

\section{Hasil}

Selama 6 bulan penelitian, terdapat 715 bayi baru lahir di Ruang Rawat Gabung. Dua ratus tujuh puluh tiga $(38 \%)$ bayi tidak memenuhi kriteria penelitian karena prematuritas, lepas pemantauan, diperbolehkan pulang, pulang atas permintaan keluarga, sakit, dan orangtua menolak ikut serta dalam penelitian. Terdapat $540(75,5 \%)$ bayi dengan usia gestasi $\geq 37$ minggu. Empat ratus empat puluh dua (82\%) bayi berhasil diikutsertakan dalam penelitian.

Enam bayi mempunyai kelainan kongenital lain, seperti bibir sumbing, talipes maupun tersangka sindrom. Tidak ada bayi yang lahir dengan riwayat keluarga PJB, terdiagnosis PJB saat antenatal maupun melalui pemeriksaan fisis. Karakteristik subjek penelitian tertera pada Tabel 1 .

Pada bayi berusia 24-72 jam, median $\mathrm{SpO}_{2}$ preduktal dengan dua jenis pulse oksimetri 98 (95$100) \%$, median $\mathrm{SpO}_{2}$ postduktal 98 (95-100)\% untuk oksimetri fingertip (Onyx II $\left.{ }^{\circledR}\right)$ dan 99 (95-100)\% untuk oksimetri generasi baru (Masimo SET ${ }^{\circledR}$ ). Pada oksimetri preduktal, frekuensi nadi berada pada kisaran normal yaitu 131 (97-164) kali/menit menggunakan Onyx II ${ }^{\circledR}$ dan 133 (95-163) kali/menit dengan Masimo SET $^{\circledR}$. Pemeriksaan postduktal menghasilkan frekuensi nadi 130 (97-164) kali/menit dan 133 (97-163) kali/ menit dengan Onyx II $^{\circledR}$ dan Masimo SET $^{\circledR}$.

Perbedaan variasi hasil pengukuran $\mathrm{SpO}_{2}$ antara pulse oksimetri fingertip dan generasi baru diperlihatkan dengan uji Bland-Altman, Gambar 1 dan 2. Pada pemeriksaan preduktal, perbedaan $\mathrm{SpO}_{2}$

Tabel 1. Karakteristik subjek penelitian

\begin{tabular}{llcc}
\hline Karakteristik & & $\begin{array}{c}\text { Jumlah } \\
(\mathrm{n}=442)\end{array}$ & Persentase (\%) \\
\hline Jenis kelamin & Lelaki & 233 & 52,7 \\
Usia (jam) & Perempuan & 209 & 47,3 \\
& $24-48$ & 261 & 59 \\
Jenis persalinan & $>48-72$ & 181 & 41 \\
& Spontan & 190 & 43 \\
& Bedah kaisar & 227 & 51,4 \\
& Ekstraksi vakum & 19 & 4,3 \\
Usia gestasi (minggu) & Forsep & 6 & 1,4 \\
\multirow{5}{*}{ Berat lahir (gram) } & $37-41$ & 436 & 98,6 \\
& $\geq 42$ & 6 & 1,4 \\
Panjang lahir (cm) & $<2000$ & 0 & 0 \\
\multirow{2}{*}{ Nilai Apgar menit pertama } & $2000-<2500$ & 47 & 10,6 \\
& $\geq 2500$ & 395 & 89,4 \\
Riwayat keluarga dengan PJB & $<44$ & 11 & 2,5 \\
\multirow{2}{*}{ Terdiagnosis PJB secara antenatal } & $\geq 44$ & 431 & 97,5 \\
\multirow{3}{*}{ Kelainan kongenital lain } & $\leq 6$ & 19 & 4,3 \\
& Ada & 423 & 95,7 \\
Bising jantung & Tidak ada & 0 & 0 \\
& Tidak & 442 & 100 \\
& Ya & 0 & 0 \\
& Tidak & 442 & 100 \\
& Ada & 6 & 1,4 \\
& Tidak ada & 436 & 98,6 \\
& & 0 & 0 \\
& 442 & 100 \\
\hline
\end{tabular}




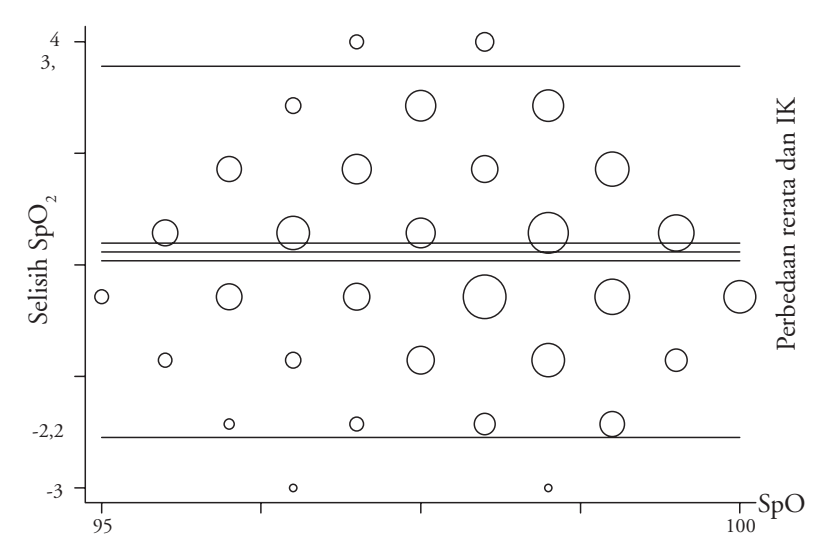

Gambar 1. Kurva Bland-Altman Perbedaan $\mathrm{SpO}_{2}$ Preduktal antara Masimo SET ${ }^{\circledR}$ dan Onyx $\mathrm{II}^{\circledR}$

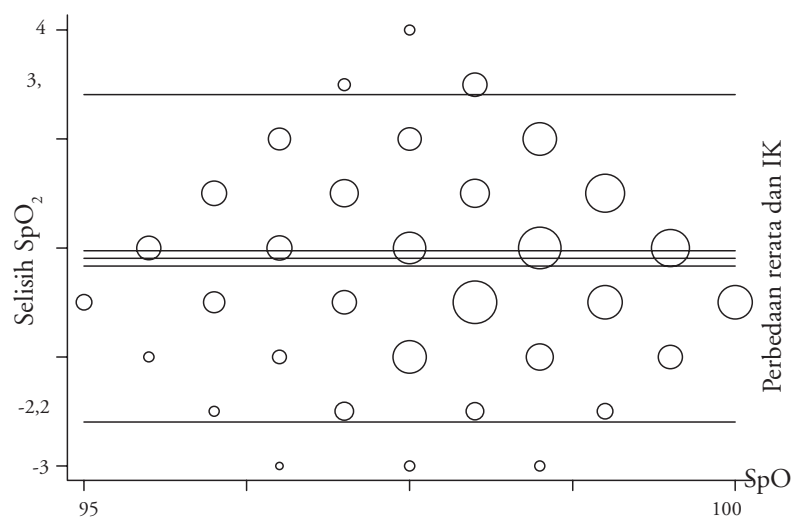

Gambar 2. Kurva Bland-Altman Perbedaan $\mathrm{SpO}_{2}$ Postduktal antara Masimo $\mathrm{SET}^{\circledR}$ dan Onyx $\mathrm{II}^{\circledR}$
SET $^{\circledR}$ dan Onyx II $^{\circledR}$ dalam kurva Bland-Altman memperlihatkan hasil tidak bervariasi, $\mathrm{p}=0,165$ (>0,005). Perbedaan rerata 0,81 (IK95\%:0,67-0,95)\% dengan batas kesesuaian -2,20\%-3,82\%.

Pada penelitian ini tidak ditemukan subjek dengan hasil deteksi positif dan tidak dijumpai bayi baru lahir dengan PJB kritis. Dengan demikian nilai diagnostik pulse oksimetri fingertip (Onyx $\mathrm{II}^{\circledR}$ ) dibandingkan generasi baru (Masimo SET ${ }^{\circledR}$ ) tidak dapat dinilai.

Pulse oksimetri fingertip (Onyx $\mathrm{II}^{\circledR}$ ) memerlukan waktu yang lebih lama untuk mencapai hasil maksimum dibandingkan dengan oksimetri generasi baru (Masimo SET ${ }^{\circledR}$ ) (Tabel 2).

Hambatan pemeriksaan sehingga oksimetri harus diulang untuk memperoleh hasil maksimal dijumpai pada 250 subjek $(56,6 \%)$. Hambatan tersebut terkait faktor bayi dan alat. Proporsi hambatan lebih banyak dijumpai saat pemeriksaan oksimetri fingertip (pengaruh gerakan bayi pada oksimetri fingertip dan generasi baru yaitu $67,6 \%$ dan $2,4 \%$, sinyal tidak terbaca $12 \%$ dan $3,2 \%$, hasil tidak stabil $12,8 \%$ dan $2 \%$ ).

\section{Pembahasan}

Banyak rumah sakit di negara maju telah menerapkan skrining oksimetri secara rutin untuk mendeteksi PJB kritis pada bayi baru lahir sebelum pulang dari rumah sakit. Di Indonesia, hal tersebut belum menjadi kebijakan rumah sakit maupun lembaga terkait. Jenis pulse oksimetri yang direkomendasikan untuk skrining

Tabel 2. Perbedaan distribusi waktu pemeriksaan pulse oksimetri fingertip (Onyx $\mathrm{II}^{\circledR}$ ) dan generasi baru $\left(\right.$ Masimo SET ${ }^{\circledR}$ )

\begin{tabular}{lccc}
\hline Waktu Pemeriksaan Oksimetri (menit) & $\begin{array}{c}\text { Onyx II } \\
\text { (median, min-maks) }\end{array}$ & $\begin{array}{c}\text { Masimo SET } \\
\text { (median, min-maks) }\end{array}$ & $\mathrm{p}^{\circledR}$ \\
\hline Preduktal $(\mathrm{n}=442)$ & $0,44(0,13-2,17)$ & $0,25(0,10-1,03)$ & $<0,001$ \\
Postduktal $(\mathrm{n}=442)$ & $0,30(0,13-2,1)$ & $0,23(0,13-1,09)$ & $<0,001$ \\
\hline
\end{tabular}

${ }^{1}$ Uji Wilcoxon

antara Masimo SET $^{\circledR}$ dengan Onyx II $^{\circledR}$ pada setiap pengukuran memperlihatkan hasil yang bervariasi, $\mathrm{p}=0,029(<0,005)$, perbedaan rerata $0,70($ IK95\%: 0,56-0,84)\% serta batas kesesuaian -2,21\%-3,61\%. Pada penelitian ini, hasil tersebut tidak bermakna klinis karena pemeriksaan dengan kedua jenis pulse oksimetri memberikan hasil deteksi yang sama.

Pada pengukuran postduktal, perbedaan $\mathrm{SpO}_{2}$ disetiap pengukuran antara oksimetri Masimo relatif tidak terjangkau ${ }^{4}$ sehingga pulse oksimetri fingertip diharapkan dapat menjadi upaya terobosan agar skrining oksimetri dapat diterapkan secara luas pada fasilitas terbatas.

Penggunaan pulse oksimetri generasi baru (Masimo SET $^{\circledR}$ ) sebagai baku emas didasarkan atas fisibilitas penelitian karena keterbatasan alat, sumber daya dan pendanaan. Masimo SET ${ }^{\circledR}$ terbukti tahan terhadap gerakan, stabil, andal, mempunyai positif palsu sangat 
rendah, serta telah banyak digunakan sebagai alat skrining PJB kritis pada penelitian sebelumnya.-9,16,17

Tidak didapatkan bayi dengan PJB kritis pada penelitian ini kemungkinan dipengaruhi oleh beberapa faktor, antara lain jumlah subjek relatif kecil, metode pengambilan subjek, dan insiden PJB kritis yang kecil. Penelitian Sendelbach $\mathrm{dkk}^{18}$ juga tidak mendapatkan bayi dengan PJB kritis melalui skrining pulse oksimetri. Dua kasus stenosis pulmonal dan 1 kasus sindrom hipoplasia jantung kiri terdiagnosis melalui pemeriksaan fisis. Penelitian tersebut mengikutsertakan subjek dalam jumlah besar, sensor direkatkan di kaki, usia subjek 4 jam, batasan $\mathrm{SpO}_{2}$ abnormal $<96 \%$, dan skrining diulang saat subjek hendak pulang dari rumah sakit. Koppel $\mathrm{dkk}^{11}$ menunjukkan prevalens PJB kritis pada populasi total 1 per 564, populasi asimtomatik yang menjalani skrining 1 per 2256, sedangkan jumlah PJB kritis yang berhasil dideteksi dengan oksimetri 3/11.281 atau 1 per 3760 yaitu 2 kasus anomali total drainase vena pulmonalis dan 1 kasus trunkus arteriosus. Ewer $\mathrm{dkk}^{8}$ memperoleh prevalensi 2,6 per 1000 kelainan hidup (53/20.055) kasus kelainan jantung mayor.

Hasil uji oksimetri dengan pulse oksimeter fingertip $\left(\right.$ Onyx $\left.\mathrm{II}^{\circledR}\right)$ dibandingkan generasi baru (Masimo SET $^{\circledR}$ ) untuk deteksi PJB kritis pada penelitian ini tidak dapat dinilai. Tidak terdapat kelompok uji/ baku emas dengan hasil deteksi positif. Penelitian lain tentang uji oksimetri serupa belum pernah dipublikasikan. Kebanyakan penelitian menilai uji diagnostik pulse oksimetri generasi baru dibandingkan dengan studi populasi atau ekokardiografi. Sensitivitas bervariasi dari tidak dapat dinilai hingga 100\% ditunjukkan oleh review sistematik Mahle $\mathrm{dkk}^{3}$. Perbedaaan metodologi tampaknya memengaruhi hasil tersebut. Selain itu, review tersebut juga mendapatkan spesifisitas tinggi 95,5 hingga 100\%. Review sistematik lain oleh Thangaratinam $\mathrm{dkk}^{10}$ pada 13 penelitian mendapatkan sensitivitas sedang $(76,5$ (IK95\%: 67,7-83,5)\%) dan spesifisitas tinggi $(99,9$ (IK95\%: 99,7-99,9)\%).

Pemeriksaan oksimetri dilakukan saat bayi tenang, tidak ada gerakan berlebihan, melawan, maupun menangis. Penelitian ini mendapatkan pemeriksaan pulse oksimetri fingertip memerlukan waktu yang lebih lama untuk mencapai hasil maksimal dengan median $0,45(0,13-2,17)$ menit dan 0,25 (0,13-1,03) menit $(\mathrm{p}<0,001)$. Penelitian O'Donnell $\mathrm{dkk}^{19}$ menggunakan Masimo SET $^{\circledR}$ pada bayi baru lahir menunjukkan rerata total waktu yang diperlukan untuk mencapai data yang akurat yaitu $25( \pm 7)$ detik. Beberapa faktor yang dapat memengaruhi waktu pencapaian hasil yaitu faktor alat, bayi, pemeriksa, dan orangtua. ${ }^{20}$

Pelaksanaan oksimetri pada penelitian ini dipengaruhi oleh faktor alat dan bayi. Hambatan terbesar tampak pada penggunaan pulse oksimeter fingertip $(92,4 \%)$. Pengaruh gerakan bayi $67,6 \%$ dan faktor alat (sinyal tidak terbaca dan hasil tidak stabil) $24,8 \%$. Oksimeter generasi baru mempunyai algoritme yang diperbaiki sehingga dapat menyaring sinyal yang tidak diperlukan. Beberapa penelitian melaporkan keandalan oksimeter generasi baru (Masimo SET ${ }^{\circledR}$ ) dalam mengatasi pengaruh gerakan. ${ }^{16,17}$

\section{Kesimpulan}

Pemeriksaan oksimetri pada bayi baru lahir sebelum pulang dari rumah sakit belum mendeteksi bayi dengan PJB kritis. Tidak didapatkannya hasil deteksi positif menyebabkan uji diagnostik tidak dapat dinilai. Hasil pemeriksaan $\mathrm{SpO}_{2}$ pulse oksimetri fingertip dan generasi baru bervariasi secara statistic, tetapi secara klinis untuk skrining PJB kritis tidak bermakna. Meskipun masih memerlukan penelitian lebih lanjut, pulse oksimetri fingertip dapat menjadi alternatif oksimetri untuk skrining PJB kritis pada bayi baru lahir dengan mempertimbangkan beberapa keterbatasan terutama pengaruh gerakan bayi dan faktor alat (sinyal tidak terbaca dan hasil tidak stabil).

\section{Daftar pustaka}

1. Liske MR, Greeley CS, Law DJ, Walsh WF, dkk. Report of the tennessee task force on screening newborn infants for critical congenital hear disease. Pediatrics 2006;118:1250-7.

2. Hoffman JIE. It is time for routine neonatal screening by pulse oximetry. Neonatol 2011;99:1-9.

3. Mahle WT, Newburger JW, Matherne GP, Grosse SD, dkk. Role of pulse oximetry in examining newborns for congenital heart disease: a scientific statement from the AHA and AAP. Pediatrics 2009;124:823-36.

4. Wren C, Reinhardt Z, Khawaja K. Twenty-year trends in diagnosis of life-threatening neonatal cardiovascular malformations. Arch Dis Child Fetal Neonatal 2008;93:33-5. 
5. Abu-Harb M, Hey E, Wren C. Death in infancy from unrecognised congenital heart disease. Arch Dis Child 1994;71:3-7.

6. Badan Pusat Statistik. Perkembangan beberapa indikator utama sosial-ekonomi Indonesia November 2010. Jakarta: Badan Pusat Statistik;2010.h.9-45.

7. de-Wahl Granelli A, Wennergren M, Sandberg K, Östman-Smith I, dkk. Impact of pulse oximetry screening on the detection of duct dependent congenital heart disease: a Swedish prospective screening study in 39,821 newborns. BMJ 2009;338:1-12.

8. Ewer AK, Middleton LJ, Furmston AT, Khan KS, dkk. Pulse oximetry screening for congenital heart defects in newborn infants (PulseOx): a test accuracy study. Lancet 2011;378:785-94.

9. Meberg A, Brügmann-Pieper S, Due R Jr, Sielberg IE, dkk. First day of life pulse oximetry screening to detect congenital heart defects. J Pediatr 2008;152:761-5.

10. Thangaratinam S, Brown K, Zamora J, Khan KS, Ewer AK. Pulse oximetry screening for critical congenital heart defects in asymptomatic newborn babies: a systematic review and meta-analysis. The Lancet 2012;379:245964.

11. Koppel RI, Druschel CM, Carter T, Bierman FZ, dkk. Effectiveness of pulse oximetry screening for congenital heart disease in asymptomatic newborns. Pediatrics 2003;111:451-5.

12. Hoke TR, Donohue PK, Bawa PK, Byrne BJ, dkk. Oxygen saturation as a screening test for critical congenital heart disease: a preliminary study. Pediatr Cardiol 2002;23:403-9.

13. Ortega R, Hansen CJ, Elterman K, Woo K. Pulse oximetry. N Engl J Med 2011;364:33-7.

14. Knowles R, Griebsch I, Dezateux C, Brown J, Bull C, Wren C. Newborn screening for congenital heart defects: a systematic review and cost-effectiveness analysis. Health Technol Assess 2005;9:1-152.

15. Nonin. Fingertip pulse oximetry. Diakses pada tanggal 12 Mei 2013. Diunduh dari: http://www.nonin.com/Oximetry/ Fingertip.

16. Hay WW, Rodden DJ, Collins SM, Melara DL, Hale KA, Fashaw LM. Reliability of conventional and new pulse oximetry in neonatal patients. J Perinatol 2002;22:360-6.

17. Sahni R, Gupta A, Rosen TS. Motion-resistant pulse oximetry during circumcision in neonates. Arch Dis Child Fetal Neonatal 2003;88:505-8.

18. Sendelbach DM, Jackson GL, Lai SS, Fixler DE, Stehel EK, Engle WD. Pulse oximetry screening at 4 hours of age to detect critical congenital heart defects. Pediatrics 2008;122:1-6.

19. O’Donnell CPF, Kamlin COF, Davis PG, Morley CJ. Obtaining pulse oximetry data in neonates: a randomised crossover study of sensor application techniques. Arch Dis Child Fetal Neonatal 2005;90:84-5.

20. Bradshaw EA, Cuzzi S, Kiernan SC, Nagel N, Becker JA, Martin GR. Feasibility of implementing pulse oximetry screening for congenital heart disease in a community hospital. J Perinatol 2012;32:710-5. 